\title{
P-QOL questionnaire in Thai version: response to comments by Wiwanitkit
}

\author{
Tarinee Manchana
}

Received: 23 April 2010 /Accepted: 3 May 2010/Published online: 18 May 2010

(C) The International Urogynecological Association 2010

\section{Dear Editor,}

I would like to respond to Dr. Wiwanitkit's comments [1] on our article [2] as follows:

Comment: From a few selective tested subjects in this work, it is questionable that the questionnaire can be generalized for the general Thai population.

Response: Although the subjects included in this study were selected from patients who attended the gynecologic outpatient clinic at our hospital, the characteristics represented in this study are not different from the general Thai population. Furthermore, the questions in this questionnaire are simple and do not require a high education level. A linguist from the Institute of Language of Chulalongkorn University helped with the translation into Thai and checked for language validity. Therefore, our questionnaire can be used in the general population.

Comment: There is no report on questionnaire testing and reliability test by statistical means. Nevertheless, evidence of content validity, construct validity, concurrent validity, internal consistency reliability and stability should be provided.
Response: We have already tested for consistency and reliability. Statistical value was also shown on page 3 and in Table 3.

Comment: It is also questionable whether the demographic background of the subjects has any effect to the effectiveness of the questionnaire.

Response: Factors such as illiteracy and extreme old age who are unable to read or write clearly may influence the response. However, we eliminated these by allowing relatives or health personnel who were not familiar with the questionnaires to assist patients in answering the questions.

\section{References}

1. Wiwanitkit V (2010) P-QOL questionnaire in Thai version. Int Urogynecol J Pelvic Floor Dysfunct. doi:10.1007/s00192-0101166-5

2. Manchana T, Bunyavejchevin S (2010) Validation of the Prolapse Quality of Life (P-QOL) questionnaire in Thai version. Int Urogynecol J Pelvic Floor Dysfunct. doi:10.1007/s00192-010$1107-3$

T. Manchana $(\bowtie)$

Urogynecology Division, Department of Obstetrics and

Gynecology, Faculty of Medicine, Chulalongkorn University,

1873 Rama IV Road, Patumwan,

Bangkok 10330, Thailand

e-mail: t_manchana@hotmail.com 